\title{
PAP Smear and Colposcopic Evaluation of Uterine Cervix
}

\author{
Denisa Bajraktari ${ }^{1}$, Odeta Hoxhaj ${ }^{2}$ \\ ${ }^{1}$ Obstetric Gynecologic Hospital "Queen Geraldine” Tirana, Albania \\ ${ }^{2}$ Faculty of Natural Sciences
}

\begin{abstract}
The clinical use of colposcopy for the evaluation of cervical cytologic abnormalities allows the identification and successful management of most premalignant cervical lesions. The aim of this study is to describe the colposcopic features in the cervices of persistent inflammatory cellular changes on Pap smear and epithelial cell abnormalities by colposcopic biopsy. This is a prospective analytical study of 167 patients conducted in the Obstetric Gynecologic University Hospital "Queen Geraldine", in Tirana, Albania during the period 2014 and 2015. The mean age was 36 years and the mean parity was 2.2. The most common symptom was vaginal discharge followed by pelvic pain and in $45 \%$ of the patients the clinical diagnosis was pelvic inflammatory disease. Abnormal uterine bleeding and erosion of the cervix also contributed to inflammatory smear in approximately $20 \%$ of the patients. Cervical cancer screening was proved to be an important part of preventive health care of women.
\end{abstract}

Keywords: uterine cervix, non-specific inflammation, cellular changes

\section{Introduction}

The uterine cervix presents a unique opportunity to clinicians in that it is physically and visually accessible for evaluation. It demonstrates a well-described spectrum of histological and colposcopic findings from health to premalignancy to invasive cancer (1). Since nearly all cervical neoplasia occurs in the presence of human papillomavirus infection, the cervix provides the bestdefined model of virus-mediated carcinogenesis in humans to date. The clinical use of colposcopy for the evaluation of cervical cytologic abnormalities allows the identification and successful management of most premalignant cervical lesions. Its usefulness and efficacy in cancer prevention is undisputed and unparalleled. Interest in colposcopy has grown steadily along with the incidence of cervical disease during the past three to four decades. More and more primary care physicians are receiving training in colposcopy. This has, no doubt, improved efforts to identify and manage cervical neoplasia appropriately. Chronic inflammation, either specific or non-specific, has been shown to be associated with malignancy and was thought to be one of the factors responsible for carcinogenesis. Persistent inflammation leads to increased cellular turnover, especially in the epithelium, and provides a selection pressure that results in the emergence of cells that are at a high risk for malignanttransformation(2). Inflammatory Pap smear is the most common report the gynecologist receives even when the cervix appears normal $(3,4)$. The original Papanicolau classification of class 2 smears denotes inflammation and the recommendation is to repeat the smear after treating the infection (5). However, this does not specify the type of infection, and the present reporting of Pap smear by the Bethesda system reports on specific infections and classifies it under benign cellular changes (6).The cervical screening algorithm for benign cellular changes recommends treatment of infection if indicated and performing a repeat Pap smear in 4 to 6 months time and, if the inflammatory changes persist, to subject the patient to colposcopy $(7,8)$. In practice, however, this is not always followed, especially in developing countries. The significance of cervical cytology with atypia has been extensively studied. There is a great controversy regarding the optimal management of women with persistent inflammatory changes without atypia, some considering it less likely to be associated with dysplasia and others recommending further evaluation as it is associated with a high incidence of cervical intraepithelial neoplasia (CIN) $(9,10)$. Hence, we have undertaken this study with the following objectives: (1) to study the colposcopic features in the cervices of persistent inflammatory cellular changes on Pap smear (2) to study epithelial cell abnormalities by colposcopic biopsy of abnormal areas in such cases and (3) to determine the existence of significant cervical intraepithelial lesions or invasive carcinoma in patients with persistent inflammatory Pap smear.

\section{Materials and Methods}

This is a prospective analytical study of 167 patients conducted in the Obstetric Gynecologic University Hospital "Queen Geraldine", in Tirana, Albania during the period 2014 and 2015. One hundred and sixty seven women who showed persistent inflammatory changes on Pap smear were included in the study. Patients with persistent inflammatory changes with atypical or dysplastic cells, patients with Diabetes mellitus, pregnant women and patients with previous cervical surgery were excluded. The study was approved by the Institute Scientific and Ethical Committee. Patients with a report of inflammatory Pap smear were selected at random for initial recruitment. These patients were advised to use Clotimazole or Betadine vaginal pessaries for a minimum of 6 days. Those with a clinical diagnosis of chronic pelvic inflammatory disease and showing inflammatory Pap smear were given Doxycycline and Metronidazole for a minimum period of 14 days along with vaginal pessaries. A repeat Pap smear was performed after a period of 2 weeks with Ayer's wooden spatula. No preparation of the cervix was undertaken at the time of sampling and women were not menstruating or using any 


\section{International Journal of Science and Research (IJSR) \\ ISSN (Online): 2319-7064}

Index Copernicus Value (2013): 6.14 | Impact Factor (2015): 6.391

vaginal douche or vaginal contraceptives at the time of sampling. If inflammatory cellular changes were reported again on the repeat Pap smear, these patients were subjected to colposcopic examination after taking informed consent.The woman was kept in a dorsal position and the cervix was exposed by inserting a Cusco's speculum. Excess mucus was wiped off with a cotton swab soaked in saline. Five percent acetic acid was applied to the cervix and it was visualized using a binocular colposcope under 40X magnification. Biopsies were taken from the abnormal areas (acetowhite areas and vascular abnormalities like fine punctuations, coarse punctuations, mosaic and areas showing atypical vasculature) and an endocervical curettage was performed. All the specimens were subjected to histopathological examination.

\section{Results and Discussion}

The clinical profile of the patients is shown in table 1.The mean age was 36 years and the mean parity was 2.2 . The most common symptom was vaginal discharge followed by pelvic pain and in $45 \%$ of the patients the clinical diagnosis was pelvic inflammatory disease. Abnormal uterine bleeding and erosion of the cervix also contributed to inflammatory smear in approximately $20 \%$ of the patients. Regarding the colopscopic features of patients with persistent inflammatory Pap smears the most common feature was acetowhiteness (40\%) followed by a combination of acetowhiteness and vascular abnormality (23\%). Colposcopy was normal in ten patients and hence no biopsy was taken. Erosion was confirmed by colposcopy in $11 \%$ of the patients. Biopsy was also not performed when the margins of erosion were regular and these accounted for five cases. Regarding the correlation of inflammatory Pap smear with coloposcopic biopsy results the most common biopsy result in patients with inflammatory Pap smear was chronic cervicitis (26\%). Regarding the correlation between clinical symptomatology and colposcopic feature the most common colposcopic feature is acetowhiteness followed by a combination of acetowhite areas and vascular abnormality, irrespective of the symptoms. Of the patients who presented with pelvic pain, $44 \%$ showed acetowhite areas and $22 \%$ showed a combination of acetowhite areas and vascular abnormality. This is slightly higher than the patients presenting with vaginal discharge per vaginum who showed acetowhite areas in $31 \%$ of the cases and a combination of acetowhite areas and vascular abnormality in $24 \%$ of the cases. Erosion was more common in patients with vaginal discharge than in those with pelvic pain. Regarding the results of colposcopic biopsy in correlation with symptomatology, patients who presented with vaginal discharge, the most common diagnosis was chronic cervicitis followed by HPV lesions in $17 \%$ and CIN 1 in another $17 \%$ of the cases. Patients with abnormal uterine bleeding also showed a significantly increased incidence of CIN (20\%). Of the benign lesions, chronic cervicitis and HPV changes were common. Acanthosis, koilocytosis, chronic cervicitis with koilocytosis, squamous metaplasia with koilocytosis, acanthosis with koilocytosis and koilocytic atypia were grouped under HPV changes.

\section{Conclusion}

Cervical cancer screening was proved to be an important part of preventive health care of women. Attempts are being made to improve the efficacy of the screening programme to decrease the morbidity and mortality due to cervical cancer. The cervical screening algorithm for benign cellular changes on Pap smear recommends treatment of infection if indicated and a repeat Pap smear in $4-6$ months time, and, if the inflammatory changes still persist, to subject the patient to colposcopy. However, in practice, this is not followed, especially in developing countries like ours, where proper screening protocols are not available/followed. Hence, a good number of patients in the pre-malignant stage are being missed. Most Obstetrician Gynecologists do not review the Pap smear result with the cytologists and $41 \%$ do nothing when inflammatory Pap smear is reported. Only $11 \%$ treat the infection and repeat Pap smear and 24\% treat infection and do not repeat Pap smear (11). There are very few studies in the literature where the incidence of premalignant and malignant lesions was looked into in cases of inflammatory Pap smear. Inflammation can obscure few malignant cells and may result in high false negative rates and the same may be reduced by employing liquid based cytology (12). However, it was reported that liquid based cytology was not cost-effective for developing countries and the recent studies did not report a statistically significant difference of accuracy between conventional Pap test and liquid based cytology (13).The main reason for false-negative reports of cytology were found to be sampling errors, with sampling errors as high as $42.5 \%$ being suboptimal and $17.5 \%$ being inadequate for interpretation (14). Mc Lachlan and colleagues studied the colposcopic features and biopsy results of 102 women with persistent inflammatory Pap smears and found $19 \%$ cases of CIN 2 or worse (15). This is almost similar to the present study.

\section{References}

[1] Society of Gynecologic Oncology (February 2014), "Five Things Physicians and Patients Should Question", Choosing Wisely: an initiative of the ABIM Foundation (Society of Gynecologic Oncology), retrieved 19 February 2013, which cites

[2] Rimel, B. J.; Ferda, A.; Erwin, J.; Dewdney, S. B.; Seamon, L.; Gao, F.; Desimone, C.; Cotney, K. K.; Huh, W.; Massad, L. S. (2011). "Cervicovaginal Cytology in the Detection of Recurrence After Cervical Cancer Treatment". Obstetrics \& Gynecology 118 (3): 548. doi:10.1097/AOG.0b013e3182271fdd.

[3] Tergas, A. I.; Havrilesky, L. J.; Fader, A. N.; Guntupalli, S. R.; Huh, W. K.; Massad, L. S.; Rimel, B. J. (2013). Gynecologic Oncology 130 (3): 421. doi:10.1016/j.ygyno.2013.05.037.

[4] Principles and Practice of Colposcopy. JP Medical Ltd. 2011. ISBN 9789350250945.

[5] Spracklen, C. N.; Harland, K. K.; Stegmann, B. J.; Saftlas, A. F. (2013). "Cervical surgery for cervical intraepithelial neoplasia and prolonged time to conception of a live birth: A case-control study". BJOG: an International Journal of Obstetrics \& Gynaecology 120 (8): 960-965. doi:10.1111/1471-0528.12209. PMC 3691952 . PMID 23489374. 


\section{International Journal of Science and Research (IJSR) \\ ISSN (Online): 2319-7064}

Index Copernicus Value (2013): 6.14 | Impact Factor (2015): 6.391

[6] Chase DM, Kalouyan M, DiSaia PJ (May 2009). "Colposcopy to evaluate abnormal cervical cytology in 2008". Am. J. Obstet. Gynecol. 200 (5): 472-80.

[7] Engelstad LP, Stewart SL, Nguyen BH, Bedeian KL, Rubin MM, Pasick RJ, et al. Abnormal Pap smear follow-up in a high-risk population. Cancer Epidemiol Biomarkers Prev. 2001;10:1015-20. [PubMed]

[8] Moss SF, Blaser MJ. Mechanisms of Disease: Inflammation and origins of cancer. Nat Clin Pract Oncol 2005;2:907.

[9] Kiviat NB, Paavonen JA, Brockway J, Critchlow CW, Brunham RC, Stevens CE, Cytologic manifestations of cervical and vaginal infections. I.Epithelial and Inflammatory changes. JAMA 1985;253:989-96. ]

[10] Atikson KM. benign cellular changes. In: Bonfigilo T, Erogen YS Editors. Gynaecologic Cytopathology. Philadelphia: Lppincot Raven Publishers; 1997. p. 3342.

[11]ACOG Practice Bulletin. clinical management guidelines for Obstetrician and Gynecologist Cervical Cytology screening Obstet Gynecol 2003;102:417-27.

[12] Marchand L, Van Dinter M, Mundt M, Dingel W, Klein G. Current cervical cancer screening practices of Dane Country, Wsconsin Primary care clinicians. WMJ 2003;102:3540.

[13] ACOG Committee on Practice Bulletins--Gynecology. ACOG Practice Bulletin no. 109: Cervical cytology screening .Obstet Gynecol 2009;114:1409-20.

[14] Vassilakos P. Management of Suboptimal Cytologic smears: Persistent inflammatory smears. Acta Cytol 1998;42:1481.

[15] McLachalan N, Patwardhan JR, Ayer B, Pacey NF. Management of suboptimal cytologic smears: Persistent inflammatory smears. Acta Cytol. 1994;38:5316.

Table 1: Citological findings in Pap smear

\begin{tabular}{|c|c|c|}
\hline Clinical characteristic & $\mathrm{N}$ & $\%$ \\
\hline Mean age & 34 years & \\
\hline Parity & 2.2 & \\
\hline Simptomatology & & \\
\hline White discharge per vaginum & 70 & 42 \\
\hline Pelvic pain & 43 & 26 \\
\hline AUB & 18 & 11 \\
\hline Post coital bleeding & 8 & 5 \\
\hline Mass descending per vaginum & 5 & 3 \\
\hline Post-menopausal bleeding & 5 & 3 \\
\hline Dysmenorrhea & 4 & 2.5 \\
\hline Clinical diagnosis & & \\
\hline PID & 53 & 32 \\
\hline AUB & 33 & 20 \\
\hline Cervix erosion & 33 & 20 \\
\hline Unhealthy cervix & 20 & 12 \\
\hline Uterovaginal prolapse & 5 & 3 \\
\hline Ovarian cyst & 5 & 3 \\
\hline Fibroid uterus & 3 & 2 \\
\hline
\end{tabular}

